\title{
Work-related Identity Discrepancy and Work Withdrawal Behavior: the Mediation Effect of Negative Emotion ${ }^{1}$
}

\author{
Chang-e Liu \\ Xiao Yuan \\ Mengning Zhang Chenhong Hu \\ School of Business \\ Mobile E-business Collaborative Innovation Center of Hunan Province \\ Key Laboratory of Hunan Province for Mobile Business Intelligence \\ Hunan University of Commerce \\ Changsha, China
}

\begin{abstract}
This study examines the role of negative emotion in explaining the association between work-related identity discrepancy and work withdrawal behavior. Drawing on the cognitive evaluation theory of emotion, we hypothesize a mediating model in which work-related identity discrepancy is associated with work withdrawal behavior. In examining this model, we further establish a link between work-related identity discrepancy and work withdrawal behavior and identify one pathway to explain this relationship. Based on a sample of 510 Chinese employees, we find support for a mediating model in which the association between work-related identity discrepancy and work withdrawal behavior via negative emotion. Findings from the current study contribute to our exploring the black box between work-related identity discrepancy and work withdrawal behavior.
\end{abstract}

Keywords: Work-related identity discrepancy; Work withdrawal behavior; Negative emotion; Cognitive evaluation theory of emotion

\section{Introduction}

With the rapid development of economy, change of personnel is more common than ever, especially the change of organizational leadership. For example, former Nintendo executives left for Microsoft in 2019, and more than 40 Tesla executives left successively in 2018. Meanwhile, frequent changes of leaders have an impact on the organization and its members. Existing studies have shown that leaders' resignation will destroy the development atmosphere of the organization and lead to the spread of resignation, reduce the organizational identification of employees who have high-quality leadership exchange relationship with former leaders, and increase their turnover intention (Shapiro et al.,2016). In addition, leaders in China usually establish their own "small circle" in the organization under the influence of the traditional "circle culture", which mainly presents a differential order pattern with leaders as the center and spreading outwards (Lin et al.,2016). And in the circle, the members are the "insiders" of the leaders, and the members outside the circle are the "outsiders". The leader shows more concern for "insiders" and offers more support for their work, thus the members have more resources than those outside the circle. However, when the core leader of the "circle" leaves, not only will the members leave together with the former leader (Heaphy, 2018;Shuai, 2016), but some turbulence may occur to organizations (Shen \& Cannella, 2003); what's worse, some who remain in the circle may lose their resources and work identities, resulting in work-related identity discrepancy to workers and incalculable losses to the organization.

Work-related identity discrepancy refers to the gap among the actual self, the ideal self, and the ought self caused by external events that break the cognitive balance of the existing work identity (Swann et al., 2009). And work-related identity discrepancy discussed in this research is not caused by the change of employees themselves but specifically refers to the situation where the replacement of superior leaders causes the gap in employees' self-cognition. When some employees have work-related identity discrepancy, they may carry out self-adjustment, which contribute to "good adaptability" or "bad adaptability".

\footnotetext{
${ }^{1}$ This study was funded by a research grant from the NSFC (71672056;71472062). And supported by Hunan Provincial Innovation Foundation For Postgraduate(CX20190902).
} 
Those with good adaptability can adjust their good state and continue to exert their strength for the organization. But others either quit their jobs or withdraw from their jobs, leading to the termination of their career development. Moreover, previous studies also showed that maladjustment about work-related identity discrepancy will lead to various mental health problems, such as emotional anxiety(Higgins, 1999; Heppen \& Ogilvie, 2003), depression (Amico et al., 2004), decreased personal happiness (Ryff, 1991), work engagement and employee helping behaviors (Li \& Xia, 2014), and hinder organizational change (Nag et al., 2007). Although maladjustment can cause such serious consequences, there is little research on work-related identity discrepancy at present, especially on its outcome variables, such as work withdrawal behavior. Petriglieri (2011) points out that withdrawing from existing identity may be an effective strategy to reduce identity threat when individuals perceive that positive self-identity is threatened. Therefore, this research holds that when employees are confronted with work-related identity discrepancy, the loss of their original identity will bring them threats and pressure, and increase the consumption of mental resources, which will lead to the behavioral tendency of employees to withdraw from their work status and then work withdrawal behavior.

Work withdrawal behavior refers to employees' psychological and behavioral withdrawal from work. (Lehman \& Simpson, 1992). Undoubtedly, employees' work withdrawal behavior will bring adverse effects to the organization. However, there nearly not exist research on work-related identity discrepancy and work withdrawal behavior in the past, so that the mechanism between the two is almost a completely unknown black box. In view of this, this research attempts to clarify the logical relationship between work-related identity discrepancy and work withdrawal behavior and to reveal the black box of influencing factors between them from the cognitive evaluation theory of emotion.

Cognitive evaluation theory of emotion was put forward by Lazarus and Folkman (1984) first. According to the theory, when an individual encounter a potential stressor, a cognitive process will be automatically triggered in his mind to evaluate the potential threat or challenge of the stressor to him, thus a specific emotional response is produced, which will further affect the individual's subsequent behavioral response. Furthermore, previous research has pointed out that employees' behaviors in the workplace are influenced by rational thinking as well as emotions. However, there was not enough research which pays reasonable attention to the changes in employees' emotions (Ashkanasy \& Humphrey, 2011; Barsky et al., 2011). This research argues that the work-related identity discrepancy will bring pressure to employees, leading to their work withdrawal behavior, which may be affected by employees' negative emotion.

In sum, with negative emotion as mediation variables, this study discusses the culture of "circle" under the leadership change caused by the employees' work-related identity discrepancy and work withdrawal behavior mechanism. Moreover, the contribution of this study is reflected in two aspects. Firstly, it enriches the nomological network of identity research theoretically. The second is to provide guidance for enterprises to deal with the negative impact caused by work-related identity discrepancy.

\section{Literature Review and Hypotheses}

\subsection{The effect of work-related identity discrepancy on work withdrawal behavior}

In the past ten years, the research on the work-related identity discrepancy gradually emerges due to the influence of flexible career and borderless career. Previous studies have shown that work-related identity discrepancy tends to stress individuals and lead to negative behaviors. For example, Nahum-Shani \& Bamberger (2019) found that the difference in working status caused by retirement would bring anxiety and pressure to retirees during the transition period of their status, causing them to have behaviors which escape from reality. Therefore, when leaders are replaced, employees' work-related identity discrepancy may lead to their work withdrawal behavior to escape from reality.

Work withdrawal behavior is not a simple single behavior, but a sequence of behaviors, consisting of multiple behaviors. It starts from occasional psychological withdrawal and gradually expands to behavioral withdrawal, and the degree of withdrawal increases successively (Gupta \& Jenkins, 1991; Lehman \& Simpson, 1992). Podsakoff \& LePine (2007) believed that work pressure would lead to the generation of work withdrawal behavior. Therefore, we speculated that the loss of work identity such as work-related identity discrepancy would cause stress to employees and lead to the generation of work withdrawal behavior.

Cognitive evaluation theory of emotion holds that emotion is the product of the interaction between people and environment, when people face causing their current pressure source, the first thing they will do is to start their own cognitive system to evaluate the pressure source, resulting in a specific emotional response, and this kind of emotional response will further influence the individual follow-up behavioral responses (Dewe, 1991). Employees often have negative evaluations in the face of organizational change, especially the "insider" of the former leader. That is to say, the "insider" of the former leader occurs work-related identity discrepancy occurs. 
Therefore, employees will start their own cognitive system to evaluate work-related identity discrepancy, and then generate emotions to affect their behaviors. Meanwhile, the employee who has work-related identity discrepancy often leads to employee cognitive dissonance, which needs more psychological resources to adapt to the new leader. Consequently, they will have certain views or take certain actions to balance their own cognition, and the occurrence of work withdrawal behavior is one of them. Hence, we propose hypothesis 1:

Hypothesis 1:Work-related identity discrepancy has a positive effect on work withdrawal behavior.

\subsection{The mediating effect of negative emotions}

Negative Emotion is a basic subjective experience of unpleasant mood, which includes a variety of annoying states, such as anger, grief, anxiety (Waston et al., 1988). Previous studies have shown that work-related losses often lead to sadness -- a negative emotional reaction to the loss of something important -- and a period of very contradictory identities (Mael \& Ashforth, 2001). The replacement of leaders will take away the original "insiders" identity and resources of employees, resulting in employees not only facing psychological pressure, but facing heavier work pressure, and negative emotion arising spontaneously. Therefore, we infer that work-related identity discrepancy can cause negative emotion. In addition, some studies have also pointed out that negative emotion is antecedent that affects work withdrawal behavior (Chi \& Liang, 2013; Yu et al., 2019).

Meanwhile, according to the cognitive evaluation theory of emotion, when individuals encounter stressors, they will conduct cognition-evaluation, and the process of generating emotions and behaviors can be divided into two parts: initial evaluation and secondary evaluation. In the initial evaluation stage, individuals only care about whether the event is beneficial to themselves or consistent with their goals. Since, confronted with leadership change event, if the employee will view work-related identity discrepancy as a challenge, think leadership change is just the way the organization develops, or think that they have enough confidence and ability to face the negative effect brought by work-related identity discrepancy, the employee will have a positive mood, and put into the same as the previous attention and enthusiasm into the work; But if the staff will view work-related identity discrepancy as a threat to identity, they will think that the replacement of leaders will affect their career, or that they do not have enough confidence and ability to cope with the negative impact of organizational change events, thus increasing their psychological cognitive burden, and then employees will have negative emotion. For former leaders' inner circle members, the work-related identity discrepancy is obviously a huge potential threat, which can cause negative emotion among employees. In addition, the theory also holds that individuals will have specific emotional reactions after cognitive evaluation of potential stressors, and such emotional reactions will further affect the individual's subsequent behavioral reactions. Therefore, we speculate that when employees suffer from work status difference incidents, negative emotion will occur and aggravate the occurrence of work withdrawal behavior. And relevant studies have pointed out that emotions will affect employee behaviors (Wang et al., 2012). When negative emotion occurs, they tend to cause the loss of individual psychological resources. When the old leader leaves and the new leader takes office, employees will enter a period of identity contradiction, and negative emotion will consume employees' mental resources for a long time. Furthermore, employees will balance this out for their own physical and mental health and restore their psychological resources through withdrawal (Hobfoll, Halbesleben, Neveu, \& Westman, 2018). Hence, we propose hypothesis 2:

Hypothesis 2: Negative emotion mediates the effect of Work-related identity discrepancy on work withdrawal behavior.

Based on the above analysis, this research establishes the conceptual model in following figure 1.

\begin{tabular}{|c|c|c|c|}
\hline $\begin{array}{c}\text { Work-related } \\
\text { identity discrepancy }\end{array}$ & $\rightarrow$ Negative emotion \\
& $\begin{array}{c}\text { Work withdrawal } \\
\text { behavior }\end{array}$ \\
\hline
\end{tabular}

Figure 1

\section{Research Design}

\subsection{Participants and Procedure}

We distributed 841 copies of the survey form; 510 valid responses were collected, giving a response rate of $60.64 \%$. Of the valid respondents, $40.78 \%$ were men and $59.22 \%$ women. The average age of the respondents was 30.31 years (SD $=9.19$ ), ranging from 19 to 63 years. In terms of education, $36.86 \%$ of the respondents had a master's degree or above, $62.35 \%$ a bachelor's degree, and $0.01 \%$ had a high school diploma or below. Of the respondents, $52.74 \%$ were employees, $24.90 \%$ supervisors, $19.02 \%$ middle-level managers, $3.33 \%$ and senior managers. 


\subsection{Measures}

In order to ensure the reliability of measurement tools, we used the mature scales which other researchers have developed. All scales were scored by Likert 5 points ( $1=$ "strongly disagree"; $5=$ "strongly agree"). All scales in this study are described as following.

(1) Work-related identity discrepancy(WID): We measured work-related identity discrepancy with a seven-item scale, adapted from Huang (2019), that gauges the respondents' perception of leadership turnover. A sample item is "I feel that the new leader is inferior to the previous one." The scale's Cronbach's is .870 .

(2) Work withdrawal behavior (WWB): We measured perceived Work withdrawal behavior with a twelve- item scale adapted from Lehman and Simpson (1992)'s work. A sample item is "I like to talk with my colleagues about something unrelated to work." The scale's Cronbach's was .922.

(3) Negative Emotions(NE): We adopted the eight-item scale developed by Waston et al. (1988) to measure negative emotion. A sample item is "I'm always ashamed." This Scale's Cronbach's is .916.

(4) Control Variables: We controlled for respondents' demographic variables, including age, gender, education, tenure, and occupation in the organization. As previous research suggested that these variables affect employees' behavior (Thau et al., 2009).To ensure the accuracy of the results, these variables are controlled.

\section{Results}

This study uses SPSS21.0 and AMOS17.0 to analyze the data. The steps are as follows: first, doing the descriptive statistical analysis of the data; second, testing the common method bias variation, and analyzing the data problems; third, it analyzes the direct effect and the moderating effect of the negative emotions.

\subsection{Descriptive statistics and correlation analysis}

Descriptive statistics and bivariate correlations for all study variables are reported in Table 1. In line with past research, work-related identity discrepancy $(\gamma=.579, \mathrm{p}<.001)$ were positively associated with negative emotion, respectively. work-related identity discrepancy, $\gamma=.474, \mathrm{p}<.001$, and negative emotion, $\gamma=.570, \mathrm{p}<.001$, were positively associated with work withdrawal behavior.

Table 1 Means, Standard Deviations, and Correlations Among Study Variables

\begin{tabular}{llllllllll}
\hline Variable & $\mathrm{M}$ & $\mathrm{SD}$ & 1 & 2 & 3 & 4 & 5 & 6 & 7 \\
\hline 1.gender & 1.59 & .492 & & & & & & & \\
& & & & & & & & \\
2.marital status & 1.47 & .569 & -.060 & & & & & \\
& & & & & & & & \\
3.education & 3.45 & .882 & -.030 & $.276^{* *}$ & & & & \\
4.position & 3.27 & .883 & $.295^{* *}$ & $-.268^{* *}$ & $.192^{* *}$ & & & & \\
5.Relationship & 1.96 & .671 & $.159^{* *}$ & -.059 & .020 & $.195^{* *}$ & & \\
with ex-leader & 2.508 & .781 & .054 & $-.096^{*}$ & $-.091^{*}$ & .051 & .050 & & \\
6.WID & 1.999 & .731 & .073 & -.052 & $-.098^{* *}$ & -.017 & .000 & $.579^{* *}$ & \\
7.NE & 1.957 & .625 & -.047 & -.064 & $-.137^{* *}$ & -.080 & .017 & $.474^{* *}$ & $.570^{* *}$ \\
8.WWB &
\end{tabular}

Note.WID=work-related identity discrepancy, NE=negative emotions, WWB=work withdrawal behavior $* * * \mathrm{p}<0.001 ; * * \mathrm{p}<0.01 ; * \mathrm{p}<0.05$

\subsection{Common method bias}

To ensure the results, this study used Harman single factor to analyze data. This study made unscaled principal component analysis for all variables (Zhou \& Long, 2004). According to the number of factor precipitation or common factor interpretation to determine the size of the common method of deviation, in this study, five common factors (eigenvalue $>1$ ) were extracted from the test results, and the first factor explained variation is $18.51 \%$, less than $50 \%$ (recommended explained variation). It indicated that the bias problem of the common method was not serious.

\subsection{Reliability and validity analysis}

The study uses SPSS21.0 statistical analysis software to analyze the reliability and validity of scales. The results are shown in Table 2. Cronbach alpha coefficients of all scales were above 0.80 , indicating that the reliability of the scale is quite high. The KMO values of each scale were all greater than 0.60 , and the results of Bartlett spherical test were significant, and each scale cumulative variances were greater than $50 \%$, indicating good validity. 
Table 2 Reliability and Validity Analysis

\begin{tabular}{llll}
\hline Variable & Cronbach's Alpha & KMO & Cumulative Interpretation Variance \\
\hline WID & .870 & .850 & $72.17 \%$ \\
NE & .916 & .915 & $63.79 \%$ \\
WWB & .922 & .935 & $65.47 \%$ \\
\hline
\end{tabular}

Note.WID=work-related identity discrepancy, NE=negative emotions, WWB=work withdrawal $* * * \mathrm{p}<0.001 ; * * \mathrm{p}<0.01 ; * \mathrm{p}<0.05$

AMOS21.0 software was used to conduct confirmatory factor analysis, and work-related identity discrepancy (WID), negative emotion (NE) and work withdrawal behavior (WWB) were examined as independent constructs. Regarding the former comparison, the results show that the three-factor model assumed in this study has reached the acceptance criteria $\left(X^{2} / \mathrm{df}=5.560<6\right.$, RMSEA $=0.095<0.1$, IFI, TLI, CFI are greater than 0.8$)$. The results of these confirmatory factor analyses indicate three variables have good convergent validity and discriminant validity.

Table 3 Confirmatory Factor Analyses

\begin{tabular}{lllllll}
\hline Model & Factor & $X^{2} / \mathrm{df}$ & RMSEA & IFI & TLI & CFI \\
\hline 1 & three-factor model & 5.56 & 0.095 & 0.833 & 0.817 & 0.833 \\
2 & two-factor model 1 & 8.43 & 0.121 & 0.727 & 0.702 & 0.726 \\
3 & two-factor model 2 & 9.41 & 0.129 & 0.691 & 0.663 & 0.690 \\
4 & two-factor model 3 & 7.70 & 0.115 & 0.754 & 0.731 & 0.753 \\
5 & one-factor model & 11.53 & 0.144 & 0.611 & 0.578 & 0.610 \\
\hline
\end{tabular}

\subsection{Hypothesis testing}

Main effect test.

This study uses the method of hierarchical regression analysis to verify the hypothesis, as shown in Table 4, the gender, age, position, education and seniority as a control variable into the regression model. Then, the stepwise entry method is used to put the work-related identity discrepancy into the regression model. As shown in Table 4, the work-related identity discrepancy was positively correlated with work withdrawal behavior significantly $(\beta=.464, \mathrm{P}<0.001, \mathrm{M} 2)$. Thus, Hypothesis 1 is supported.

The mediating role of negative emotion.

According to Baron and Kenny (1986), a mediating effect must meet three conditions: 1) The independent variable is associated with the dependent variable and the mediator; 2) the mediator has a significant effect on the dependent variable; and 3) when the independent variable and the mediator are simultaneously substituted into the regression equation to explain the dependent variable, the effect of the mediating variable is significant and the effect of the independent variable disappears (the fully mediating effect) or weakens (partial mediating effect).

As shown in Table 4, work-related identity discrepancy is positively correlated with negative emotions $(\beta=.570, \mathrm{P}<$ .001 , M6). Meanwhile, negative emotion is positively correlated with work withdrawal behavior $(\beta=.563, \mathrm{p}<0.001$, M3). Finally, when work-related identity discrepancy and negative emotions were simultaneously entered into the regression equation, the positive effect of work-related identity discrepancy is still significant $(\beta=-.213, \mathrm{p}<0.001, \mathrm{M} 4)$, but is weakened in comparison with $\mathrm{M} 2(\beta=.464, \mathrm{P}<.001)$. These results reveal that negative emotion plays a partial mediating role between work-related identity discrepancy and negative emotion. Therefore, hypothesis 2 is supported. 
Table 4 The Main and Mediating Effects

\begin{tabular}{|c|c|c|c|c|c|c|c|}
\hline \multirow{2}{*}{\multicolumn{2}{|c|}{ Type of the Variable }} & \multicolumn{3}{|l|}{ WWB } & \multicolumn{3}{|c|}{$\mathrm{NE}$} \\
\hline & & M1 & M2 & M3 & M4 & M5 & M6 \\
\hline \multirow{5}{*}{$\begin{array}{l}\text { Control } \\
\text { variable }\end{array}$} & gender & -.057 & -.063 & $-.089^{*}$ & $-.085^{*}$ & .057 & .049 \\
\hline & marital status & .033 & .020 & -.008 & -.005 & .073 & .056 \\
\hline & education & -.086 & -.063 & -.055 & -.051 & -.056 & -.028 \\
\hline & position & -.087 & $-.093^{*}$ & -.056 & -.065 & -.056 & -.063 \\
\hline & $\begin{array}{l}\text { Relationship } \\
\text { ex-leader }\end{array}$ & with .036 & .019 & .040 & .031 & -.008 & -.029 \\
\hline Independent & WID & & $.464^{* * * *}$ & & $.213^{* * *}$ & & $.570^{* * * *}$ \\
\hline mediator & $\mathrm{NE}$ & & & $.563^{* * *}$ & $.441^{* * *}$ & & \\
\hline$F$ & & 2.891 & 20.568 & 32.918 & 33.212 & 2.535 & 33.425 \\
\hline$R^{2}$ & & $.039^{* * *}$ & $.247^{* * *}$ & $.345^{* * *}$ & $.374^{* * *}$ & $.034^{*}$ & $.348^{* * * *}$ \\
\hline$\Delta R^{2}$ & & .039 & .208 & .306 & .127 & .034 & .314 \\
\hline
\end{tabular}

BOOTSTRAP test for mediation effect.

BOOTSTRAP test. For further analyze the mediating role of validation of negative emotion, this research uses SPSS PROCESS of macro program (Hayes, 2013), the data is 5000 times repeated data sampling, under the 95\% confidence interval, the BOOTSTRAP method is used to further test the mediation effect of negative emotion, and report the mediation variable path and control after the intervening variable, the direct effect of the independent variable on the dependent variable.As shown in Table 5, the mediating effect of the test results is .173, and the confidence interval $[.160, .254]$ does not include 0 , indicating that the mediating effect of negative emotion is significant.In addition, after controlling the negative emotion of mediating variables, the direct effect of independent variable work-related identity discrepancy on dependent variable work withdrawal behavior was .173, and the confidence interval [.104,.241] did not include 0 .Therefore, negative emotion plays a mediating role between work-related identity discrepancy and work withdrawal behavior.

Table 5 Bootstrap test for mediation effect

\begin{tabular}{|c|c|c|c|c|}
\hline \multirow{2}{*}{$\begin{array}{l}\text { Mediator } \\
\text { Negative emotions }\end{array}$} & \multicolumn{4}{|c|}{ WID $(\mathrm{X}) \rightarrow \mathrm{NE}(\mathrm{M}) \rightarrow$ WWB $(\mathrm{Y})$} \\
\hline & effect & $\mathrm{SE}$ & LLCI & ULCI \\
\hline direct effect & .173 & .035 & .104 & .241 \\
\hline indirect effect & .206 & .024 & 160 & .254 \\
\hline
\end{tabular}

\section{Discussion}

This paper mainly focuses on the effect of work-related identity discrepancy on work withdrawal behavior, especially o $\mathrm{n}$ the mediating role of negative emotion. It shows that:(1) work-related identity discrepancy significantly has a positive effect on work withdrawal behavior;(2) work-related identity discrepancy significantly has a positive effect on negativ e emotion;(3) negative emotion significantly has a positive effect on negative emotion;(4)negative emotion mediates th e main effect positively.

\subsection{Theoretical implications}

Our research mainly contributes to the literature in three aspects. First, there are few studies on the relationship between work-related identity discrepancy and work withdrawal behavior in the context of China. Our findings in support of work-related identity discrepancy significantly have a positive effect on work withdrawal behavior. Hence, we found a new antecedent for work withdrawal behavior. Second, In this study, negative emotion was used as mediating variables for the first time to explore the mechanism between work-related identity discrepancy and work withdrawal behavior, revealing the black box between them. Finally, most of the research on identity difference focuses on the field of psychology in the past, such as self-difference and emotion (Higgins , 1987; Heppen \& Ogilvie, 2003), mental health (Ferrier \& Brewin, 2005), self-identity (Makros \& McCabe, 2001), personality (Moretti \& Higgins, 1990), but less on 
management. The study of identity difference in the organizational context of management is also a major contribution to this research.

\subsection{Management implications}

The results of this study show that work-related identity discrepancy has an obvious positive effect on work withdrawal. Therefore, the organization should pay more attention to the change in organizational leadership. When leaders are replaced, the organization should timely detect the changes of employees, and conduct training intervention for employees with work-related identity discrepancy to prevent employees from work withdrawal behavior. In addition, we also point out that negative emotion aggravates the association between work-related identity discrepancy and work withdrawal behavior.

Therefore, it is necessary to guide employees to establish correct cognition in the organization. For employees with negative emotion, the organization should conduct training intervention or carry out employee assistance projects to help employees correct their attitudes, maintain an optimistic and positive attitude, actively seek solutions to problems and reduce the negative impact of leadership change.

\subsection{Limitations and directions for future research}

As with all research, our study has some limitations. First, we only collect the cross-sectional data and ignore the impact of time effects on variables, which makes it difficult to test the dynamic impact of work-related identity discrepancy on work withdrawal behavior. But our hypothesis model agrees with the research conclusion, namely the leadership change can be used as a predictor of work withdrawal behavior.

The conclusion is consistent with the findings of the negative side of leadership turnover in organizations. The future researchers can use time-series design, and through empirical sampling or field test method to collect horizontal and vertical data, which will make it more accurately to grasp the relationship among variables; Second, it uses the singlesource data measurement methods and the conclusions will be influenced easily by the deviation of a common method. In this study, employee self-evaluation is used to obtain work withdrawal behavior data. However, employees are likely to consider their own face problems and have reservations in filling in the questionnaire. Therefore, other evaluation ways are more likely to restore the essence of work withdrawal behavior. In order to reduce measurement deviation, the suggestions of Podsakoff can be taken. Through protecting the privacy of interviewees, the concern to employees' evaluation will be lower. At the same time, confirmatory factor analysis was conducted on the data, and the results showed that there was a good distinction between the main variables. Therefore, in further research, we may use multisource or other assessment methods to obtain data to avoid the impact of the homologous error.

\section{References}

Shapiro, D. L., Hom, P., Shen, W., \& Agarwal, R. (2016). How do leader departures affect subordinates' organizational attachment? A 360-degree relational perspective. Academy of Management Review, 41(3), 479-502.

Amico, K. R., Bruch, M. A., Haase, R. F., \& Sturmer, P. J. (2004). Trait shyness, actual-ought self-discrepancy and discomfort in social interaction. Personality and Individual Differences, 36(7), 1597-1610.

Ashkanasy, N. M., \& Humphrey, R. H. (2011). Current emotion research in organizational behavior. Emotion review, 3(2), 214-224.

Barsky, A., Kaplan, S. A., \& Beal, D. J. (2011). Just feelings? The role of affect in the formation of organizational fairness judgments. Journal of Management, 37(1), 248-279.

Chi, S. C. S., \& Liang, S. G. (2013). When do subordinates' emotion-regulation strategies matter? Abusive supervision, subordinates' emotional exhaustion, and work withdrawal. The Leadership Quarterly, 24(1), 125-137.

Dewe, P. (1991). Primary appraisal, secondary appraisal and coping: Their role in stressful work encounters. Journal of Occupational Psychology, 64(4), 331-351.

Ferrier, S., \& Brewin, C. R. (2005). Feared identity and obsessive-compulsive disorder. Behaviour Research and Therapy, 43(10), 1363-1374.

Gupta, N., \& Jenkins Jr, G. D. (1991). Rethinking dysfunctional employee behaviors. Human Resource Management Review, 1(1), 39-59.

Heaphy, E. D., Byron, K., Ballinger, G. A., Gittell, J. H., Leana, C., \& Sluss, D. M. (2018). Introduction to Special Topic Forum: The Changing Nature of Work Relationships. Academy of Management Review, 43(4), 558-569.

Heppen, J. B., \& Ogilvie, D. M. (2003). Predicting affect from global self-discrepancies: The dual role of the undesired self. Journal of Social and Clinical Psychology, 22(4), 347-368.

Higgans, E. T. (1999). When do self-discrepancies have specific relations to emotions? The second-generation question of Tangney, Niedenthal, Covert, and Barlow (1998). 
Higgins, E. T. (1987). Self-discrepancy: a theory relating self and affect. Psychological review, 94(3), 319.

Huang, J. (2019). The Study on the Adjustment Behavior Construction of Work Identity Difference among the Former Leader's "Mr. Right" after Leadership Change. Hunan University of Commerce.

Lazarus, R. S., \& Folkman, S. (1984). Stress, appraisal, and coping. Springer publishing company.

Lehman, W. E., \& Simpson, D. D. (1992). Employee substance use and on-the-job behaviors. Journal of applied Psychology, 77(3), 309.

Lehman, W. E., \& Simpson, D. D. (1992). Employee substance use and on-the-job behaviors. Journal of applied Psychology, 77(3), 309.

Li, Y, P., \& Xia, T. (2014). The Construction of Relational Model of the New Generation Employees' Self-discrepancy, Work Attitude and Behavior. East China Economic Management, 28(11), 128-131+171.

Lin, Y, H., \& Cheng, K. (2016). Leader-member Exchange and Employees' Unethical Pro-organizational Behavior: A Differential Mode Perspective. Journal of Management Science, 29(05), 57-70.

Mael, F. A., \& Ashforth, B. E. (2001). Identification in work, war, sports, and religion: Contrasting the benefits and risks. Journal for the Theory of Social Behaviour, 31(2), 197-222.

Makros, J., \& McCabe, M. P. (2001). Relationships between identity and self-representations during adolescence. Journal of Youth and Adolescence, 30(5), 623-639.

Moretti, M. M., \& Higgins, E. T. (1990). Relating self-discrepancy to self-esteem: The contribution of discrepancy beyond actual-self ratings. Journal of Experimental Social Psychology, 26(2), 108-123.

Nag, R., Corley, K. G., \& Gioia, D. A. (2007). The intersection of organizational identity, knowledge, and practice: Attempting strategic change via knowledge grafting. Academy of Management Journal, 50(4), 821-847.

Nahum-Shani, I., \& Bamberger, P. (2019). The lingering effects of work context: Ambient work-unit characteristics and the impact of retirement on alcohol consumption. Human Relations, 72(4), 675-705.

Petriglieri, J. L. (2011). Under threat: Responses to and the consequences of threats to individuals' identities. Academy of Management Review, 36(4), 641-662.

Podsakoff, N. P., LePine, J. A., \& LePine, M. A. (2007). Differential challenge stressor-hindrance stressor relationships with job attitudes, turnover intentions, turnover, and withdrawal behavior: a meta-analysis. Journal of applied psychology, 92(2), 438.

Ryff, C. D. (1991). Possible selves in adulthood and old age: a tale of shifting horizons. Psychology and aging, 6(2), 286.

Shen, W., \& Cannella Jr, A. A. (2003). Will succession planning increase shareholder wealth? Evidence from investor reactions to relay CEO successions. Strategic Management Journal, 24(2), 191-198.

Shuai, M. (2016). Lost Trust and Dissolved Guanxi Circles: A Case Study of the Collective Resignation Event in Tianyuan Tea Company. Chinese Journal of Sociology, 36(05), 36-63.

Swann Jr, W. B., Johnson, R. E., \& Bosson, J. K. (2009). Identity negotiation at work. Research in organizational behavior, 29, 81-109.

Thau, S., Bennett, R. J., Mitchell, M. S., \& Marrs, M. B. (2009). How management style moderates the relationship between abusive supervision and workplace deviance: An uncertainty management theory perspective. Organizational Behavior and Human Decision Processes, 108(1), 79-92.

Wang, Y, Q., Long, L, R., \& Zhou, H. (2012). Organizational Injustice Perception and Workplace Deviance: Mechanisms of Negative Emotion and Traditionality. Acta Psychologica Sinica, 44(12), 1663-1676

Watson, D., Clark, L. A., \& Tellegen, A. (1988). Development and validation of brief measures of positive and negative affect: the PANAS scales. Journal of personality and social psychology, 54(6), 1063.

Yu, X, T., Chen, X., \& Wang, H. (2019). Why does Perceived Dirty Work Lead to Work Withdrawal Behavior? The Mediating Role of Negative Emotion and Work Alienation. Human Resources Development of China, 36(06), $33-47+78$. 